\title{
Velocities and Attenuations of Gas Hydrate-Bearing Sediments
}

Scientific Investigations Report 2007-5264 


\section{Velocities and Attenuations of Gas Hydrate-Bearing Sediments}

By Myung W. Lee

Scientific Investigations Report 2007-5264 


\section{U.S. Department of the Interior DIRK KEMPTHORNE, Secretary}

\section{U.S. Geological Survey \\ Mark D. Myers, Director}

\section{U.S. Geological Survey, Reston, Virginia: 2007}

For product and ordering information:

World Wide Web: http://www.usgs.gov/pubprod

Telephone: 1-888-ASK-USGS

For more information on the USGS--the Federal source for science about the Earth, its natural and living resources, natural hazards, and the environment:

World Wide Web: http://www.usgs.gov

Telephone: 1-888-ASK-USGS

Any use of trade, product, or firm names is for descriptive purposes only and does not imply endorsement by the U.S. Government.

Although this report is in the public domain, permission must be secured from the individual copyright owners to reproduce any copyrighted materials contained within this report.

Suggested citation:

Lee, Myung W., 2007, Velocities and attenuations of gas hydrate-bearing sediments: U.S. Gelogical Survey Scientific Investigations Report 2007-5264, 11p. 


\section{Contents}

Abstract
Introduction
Acknowledgments
Theory of Three-Phase Equation
Derivation of equation
Coduli of dry frame
Velocity and Attenuation Modeling
Real Data Example
Discussion
Eelocity
Attenuation

\section{Figures}

1-6 Graphs showing-

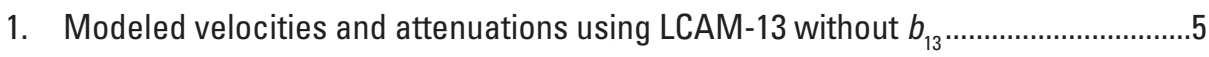

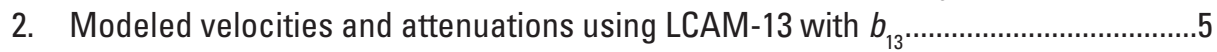

3. Measured well log velocities and attenuation at the Mallik 5L-38 well, Mackenzie Delta,Canada, and calculated velocities and attenuations using the LCAM-13

4. Estimated gas hydrate concentrations from the P-wave using the LCAM-13 and from the nuclear magnetic resonance porosities at the Mallik 5L-38 well,Mackenzie Delta, Canada .7

5. Calculated attenuation without $b_{13}$ term at 12 and $2.5 \mathrm{kHz}$ and calculated attenuation at 12 and $2.5 \mathrm{kHz}$ .8

6. Velocities and attenuations calculated from the squirt flow .....................................

\section{Table}

Table 1. Constants used for the modeling. 


\section{Selected Abbreviations Used In This Report}

$\begin{array}{ll}\text { GHBS } & \text { gas hydrate-bearing sediment } \\ \mathrm{NMR} & \text { nuclear magnetic resonance } \\ \mathrm{VSP} & \text { vertical seismic profile } \\ \mathrm{mm} & \text { millimeter } \\ \mathrm{km} / \mathrm{s} & \text { kilometers per second } \\ \mathrm{Hz} & \text { hertz } \\ \mathrm{kHz} & \text { kilohertz } \\ \mathrm{MHz} & \text { megahertz } \\ \mathrm{kg} / \mathrm{m}^{3} & \text { kilogram per cubic meter } \\ \mathrm{MPa} & \text { megapascal } \\ \mathrm{GPa} & \text { gigapascal } \\ \mathrm{cP} & \text { centipoise } \\ \mathrm{mD} & \text { millidarcy }\end{array}$




\title{
Velocities and Attenuations of Gas Hydrate-Bearing Sediments
}

\author{
By Myung W. Lee
}

\section{Abstract}

Monopole and dipole logging data at the Mallik 5L-38, Mackenzie Delta, Canada, provide a challenge for sonic velocity and attenuation models used to remotely estimate pore-space gas hydrate content. Velocity and attenuation are linked, with velocity dispersion causing increased attenuation. Sonic waveforms for Mallik 5L-38, however, show no velocity dispersion in gas hydrate-bearing layers, yet are highly attenuated. Attenuation models applied to Mallik 5L-38 data are shown to be inconsistent with the observed velocity measurements, and therefore are suspect in their ability to predict gas hydrate content. A model explicitly linking velocity and attenuation data is presented, accurately predicting gas hydrate content from velocity data alone while demonstrating that the attenuation mechanisms at the Mallik 5L-38 site have not yet been identified.

\section{Introduction}

Gas hydrate is an ice-like compound formed by the inclusion of gas within cavities in a crystal lattice formed from water molecules. Natural gas hydrate occurs in a relatively narrow depth range called the hydrate stability zone, which is delineated in large part by pressure and temperature, although other factors, such as salinity, also contribute. Methane hydrate, the most common naturally occurring gas hydrate, accumulates in permafrost and in shallow marine sediments worldwide (Pellenbarg and Max, 2000).

Based on the attenuation decrease observed in sandstones as a result of decreasing porosity (Shatilo and others, 1998), attenuation could be expected to decrease in hydrate-bearing sediments as gas hydrate content increases, reducing the water-filled porosity. This intuitive relation between attenuation and gas hydrate content runs counter to findings from well log data in permafrost (Guerin and Goldberg, 2001; Guerin and others, 2005) and marine (Guerin and others, 1999) hydrate-bearing sediments. The nonintuitive relation between sonic velocity, attenuation, and gas hydrate content is investigated here using a particularly detailed suite of geophysical well logs, including monopole and dipole measurement (Col- lett and others, 2005), obtained in 2000, from JAPEX/JNOC/ GSC Mallik 5L-38 gas hydrate research well. This well was drilled to a depth of 1,150 $\mathrm{m}$ through sands and sandstones interbedded with silt/clay at a locality on the Makenzie Delta, Canada (Dallimore and Collett, 1999).

Monopole and dipole waveform analysis at the Mallik 2L-38 well indicates that sonic waveforms show strong amplitude losses of compressional and shear waves in the interval where gas hydrate is observed (Guerin and Goldberg, 2001). The observed attenuation is also confirmed by monopole and dipole waveforms measured at the nearby Mallik 5L-38 well. Detailed waveform modeling indicates attenuation is linearly proportional to the amount of gas hydrate in the sediments (Guerin and others, 2005).

The observed attenuation at the Mallik wells appears to be opposite to the general behavior of water-saturated sediments, and vertical seismic profile (VSP) data at the Mallik 2L-38 site indicate attenuation decreases in the presence of hydrate (Lee and others, in press). To explain the nonintuitive attenuation observed in the Mallik 2L-38 well logs, Guerin and Goldberg (2001) used a wave propagation model in frozen porous media based on the percolation theory of Leclaire and others (1994). Although the predicted and observed S-wave attenuation are of the same magnitude, attenuation with respect to the gas hydrate concentration differs significantly from the observations, and the percolation model predicts much lower P- and S-wave velocities than those observed.

Guerin and Goldberg (2005) proposed a model linking velocity and attenuation based on the modified percolation theory by Carcione and Tinivella (2000) and included the squirt flow by Diallo and Appel (2000) in their formulation. The major improvement of Guerin and Goldberg (2005) over Guerin and Goldberg (2001) is (1) the inclusion of interactions between gas hydrate and host sediments through cementation, and (2) a frictional coefficient between the solid grain and gas hydrate. Guerin and Goldberg (2005) demonstrated that reasonable velocities and attenuations comparable to those observed at the Mallik 5L-38 well can be predicted.

A model was derived in which velocity and attenuation results are linked by their causal relation, demonstrating that although the causes of attenuation in well logs are not yet fully understood, gas hydrate content can be accurately estimated using velocity information. 


\section{Acknowledgments}

Well logs were acquired by Schlumberger Ltd. at the Mallik 5L-38 gas hydrate research well, which was drilled in 2002 to investigate gas hydrate in a collaborative research project among the Japan National Oil Company, Geological Survey of Canada, U.S. Geological Survey, U.S. Department of Energy, GeoForschungZentrum Potsdam, India Ministry of Petroleum and Natural Gas / Gas Authority of India, and International Scientific Continental Drilling Program. I thank W.F. Agena and W.F. Waite, USGS, for many helpful comments and suggestions.

\section{Theory of Three-Phase Equation}

The sonic velocities and attenuations discussed here are calculated from a set of equations accounting for the three phases in the system: sediment grains, gas hydrate, and liquid water. The three-phase equations are derived first, followed by derivations of the stiffness and frictional loss terms contained in the three-phase equations for compressional, $\mathrm{P}$, and shear, $\mathrm{S}$, wave speed, and attenuation.

\section{Derivation of equation}

Leclaire and others (1994) extended the Biot (1956) theory of fluid-saturated media to frozen porous media where ice and unfrozen water can coexist. Based on percolation theory, which is able to describe the ice matrix transition from a continuous to a discontinuous state during a freezing process, moduli of a matrix formed from sediment grains and ice are derived assuming there is no direct mechanical contact between grain and ice.

Carcione and Tinivella (2000) extended the percolation theory by Leclaire and others (1994) to include the potential and kinetic energy contributions because of the contact between sediment grains and ice. They referred to this theory as the modified LCA model or LCAM. However, the frictional loss caused by the relative motion between sediment grains and ice was ignored. They applied this theory for elastic wave velocities in gas hydrate-bearing sediments by replacing ice with gas hydrate.

In this report, the LCAM is extended to include the frictional loss caused by the interaction between sediment grains, referred to here simply as "grains," and gas hydrate. Moduli of a matrix formed by grains and gas hydrate were computed using dry frame moduli, similar to those recommended by Pride and others (2004), instead of the percolation theory. This report describes only the essential part of the theory of the LCAM to model velocities and attenuations of gas hydratebearing sediment (GHBS). Details of the LCAM are left to Carcione and Tinivella (2000). This report closely follows the notations of Carcione and Tinivella (2000) except that subscript $i$, which stands for ice, is changed into the subscript $h$, for gas hydrate. Note the author of this report assumes the intrinsic attenuations of gas hydrate and grains are negligible, so moduli of grains and gas hydrate are all real.

The equation of motion of the LCAM can be written as follows:

$$
\mathbf{R} \operatorname{grad} \operatorname{div} \mathbf{u}-\mu \operatorname{curl} \operatorname{curl} \mathbf{u}=\rho^{*} \frac{\partial^{2} \mathbf{u}}{\partial t^{2}}+\mathbf{A} \frac{\partial \mathbf{u}}{\partial t}
$$

where $\mathbf{u}$ is the displacement field, and $\mathbf{R}$ is the stiffness matrix, $\mu$ is the shear matrix, $\rho^{*}$ is the mass matrix, and $\mathbf{A}$ is the friction matrix. Elements of matrices are given by

$$
\mathbf{R}=\left[\begin{array}{lll}
R_{11} & R_{12} & R_{13} \\
R_{12} & R_{22} & R_{23} \\
R_{13} & R_{23} & R_{33}
\end{array}\right], \quad \mu=\left[\begin{array}{ccc}
\mu_{11} & 0 & \mu_{13} \\
0 & 0 & 0 \\
\mu_{13} & 0 & \mu_{33}
\end{array}\right],
$$

$$
\rho^{*}=\left[\begin{array}{lll}
\rho_{11}^{*} & \rho_{12}^{*} & \rho_{13}^{*} \\
\rho_{12}^{*} & \rho_{22}^{*} & \rho_{23}^{*} \\
\rho_{13}^{*} & \rho_{23}^{*} & \rho_{33}^{*}
\end{array}\right] \text {, and } \mathbf{A}=\left[\begin{array}{ccc}
b_{11}+b_{13} & -b_{11} & -b_{13} \\
-b_{11} & b_{11}+b_{33} & -b_{33} \\
-b_{13} & -b_{33} & b_{33}+b_{13}
\end{array}\right] \text {. }
$$

Note that the present theory, referred to as LCAM-13 in this report, differs from the LCAM only in elements of A matrix, where $b_{13}=0$ in the LCAM formulation. In addition to the difference in attenuation formulation, the major difference between LCAM and this report is the way of computing those elements, which will be discussed later.

P-wave velocities $(V)$ and attenuations (inverse of quality factor $Q$ ) are given by

$$
V_{p i}=\left[\operatorname{Re}\left(\sqrt{\Lambda_{i}}\right)\right]^{-1}, \quad Q_{p i}^{-1}=\frac{-2 V_{p i}}{\operatorname{Im}\left(\sqrt{\Lambda_{i}}\right)}, \quad i=1,2,3
$$

where $\Lambda_{i}$ are called the eignevalues of $\rho$ relative to $\mathbf{R}$ (Leclaire and others, 1994) and the effective density $\rho$ is defined as

$$
\rho=\rho^{*}-\frac{i \mathrm{~A}}{\omega} .
$$

S-wave velocities and attenuations are given by

$$
V_{s i}=\left[\operatorname{Re}\left(\sqrt{\Omega_{i}}\right)\right]^{-1}, Q_{s i}^{-1}=\frac{-2 V_{s i}}{\operatorname{Im}\left(\sqrt{\Omega_{i}}\right)}, \quad i=1,2
$$

where $\Omega_{i}$ are the eignevalues of $\rho$ relative to $\mu$. Therefore, all theories based on the Leclaire and others (1994) predict three $\mathrm{P}$-wave propagations and two S-wave propagations in GHBS.

If the attenuations are ignored, fast velocities of gas hydrate-bearing sediments at low frequencies can be calculated from the stiffness matrix alone and are given as follows:

$$
V_{p}=\sqrt{\frac{\sum_{i, j=1}^{3} \operatorname{real}\left(R_{i j}\right)}{\rho_{b}}} \text { and } V_{s}=\sqrt{\frac{\sum_{i, j=1}^{3} \operatorname{real}\left(\mu_{i j}\right)}{\rho_{b}}}
$$


where the bulk density of gas hydrate-bearing sediments $\left(\rho_{b}\right)$ is given by $\rho_{b}=(1-\phi) \rho_{s}+\left(1-C_{h}\right) \phi \rho_{w}+C_{h} \phi \rho_{h}$ where $\phi$ is porosity, $C_{h}$ is the pore space gas hydrate saturation, and subscripts $s, w$, and $h$ refer to sediment grains, water and gas hydrate, respectively.

\section{Moduli of dry frame}

The key component for deriving velocities from the LCAM-13 is computing the bulk and shear moduli for a frame formed by grains and gas hydrate. Carcione and Tinivella (2000) used the Kuster-Toksöz theory (1974) to drive these moduli. Here, however, moduli similar to those recommended by Pride and others (2004) and Lee (2005) are used. Lee (2005) proposed the following moduli for dry rocks:

$$
\begin{gathered}
K_{d}=\frac{K_{s}(1-\phi)}{(1+\alpha \phi)} \\
\mu_{d}=\frac{\mu_{s}(1-\phi)}{(1+\gamma \alpha \phi)} \\
\gamma=\frac{1+2 a}{1+a},
\end{gathered}
$$

with

where $K_{d}, K_{s}, \mu_{d}$, and $\mu_{s}$ are bulk modulus of dry frame, bulk modulus of the grain, shear modulus of dry frame, and shear modulus of the grain, respectively, and $\alpha$ is a consolidation parameter. As $\alpha$ increases, the dry frame moduli decrease, resulting in a velocity decrease. If $\alpha=1$, equation 7 is identical to that recommended by Pride and others (2004).

\section{Computation of moduli formed by grain and gas hydrate}

To compute stiffness and shear matrices, three different volume fractions are defined. The proportions of sediment grains $\left(\phi_{s}\right)$,water $\left(\phi_{w}\right)$, and gas hydrate $\left(\phi_{h}\right)$ are given by the following formulas:

$$
\phi_{s}=1-\phi, \phi_{w}=\left(1-C_{h}\right) \phi, \text { and } \phi_{h}=C_{h} \phi .
$$

For computing velocities, key matrix elements are $R_{11}$, $R_{33}, \mu_{11}$, and $\mu_{33}$. These matrix elements are given in the following equation by the volume fractions shown in equation 8 (Leclaire and others, 1994; Carcione and Tinivella, 2000):

$$
\begin{gathered}
R_{11}=\left[\left(1-c_{1}\right) \phi_{s}\right]^{2} K_{a v}+K_{s m}+4 \mu_{11} / 3 \\
R_{33}=\left[\left(1-c_{3}\right) \phi_{h}\right]^{2} K_{a v}+K_{h m}+4 \mu_{33} / 3 \\
\mu_{11}=\left[\left(1-g_{1}\right) \phi_{s}\right]^{2} \mu_{a v}+\mu_{s m} \\
\mu_{33}=\left[\left(1-g_{3}\right) \phi_{h}\right]^{2} \mu_{a v}+\mu_{h m}
\end{gathered}
$$

where

$$
\begin{gathered}
K_{a v}=\left[\frac{\left(1-c_{1}\right) \phi_{s}}{K_{s}}+\frac{\phi_{w}}{K_{w}}+\frac{\left(1-c_{3}\right) \phi_{h}}{K_{h}}\right]^{-1}, \\
\mu_{a v}=\left[\frac{\left(1-g_{1}\right) \phi_{s}}{\mu_{s}}+\frac{\phi_{w}}{2 \omega \eta}+\frac{\left(1-g_{3}\right) \phi_{h}}{\mu_{h}}\right]^{-1} \\
c_{1}=\frac{K_{s m}}{\phi_{s} K_{m a}}, \quad c_{2}=\frac{K_{h m}}{\phi_{h} K_{h}}, g_{1}=\frac{\mu_{s m}}{\phi_{s} \mu_{m a}}, g_{3}=\frac{\mu_{h m}}{\phi_{h} \mu_{s}},
\end{gathered}
$$

$\omega$ is an angular frequency, and $\eta$ is the viscosity of pore fluid.

To compute those four elements, the bulk and shear moduli of the matrix formed by grains $\left(K_{s m}\right.$ and $\left.\mu_{s m}\right)$ and the bulk and shear moduli of the matrix formed by gas hydrate $\left(K_{h m}\right.$ and $\left.\mu_{h m}\right)$ should be known. These moduli are difficult to evaluate. Leclaire and others (1994) used the percolation theory to derive these moduli. Carcione and Tinivella (2000) used a different equation for $\mu_{s m}$, but used the same form for $K_{s m}$. For example, Carcione and Tinivella (2000) used the following formula for $\mu_{s m}$ :

$$
\mu_{s m}=\left[\mu_{s m K T}-\mu_{s m o}\right]\left[\phi_{h} /\left(1-\phi_{s}\right)\right]^{3.8}+\mu_{s m o}
$$

where $\mu_{s m K T}$ is the shear modulus of sediment matrix calculated using the Kuster-Toksöz theory (1974) and $\mu_{\text {smo }}$ is the shear modulus of matrix at full water saturation. Carcione and Tinivella (2000) used $\mu_{s m o}=1.19$ gigapascals (GPa) in their example, whereas the equation by Leclaire and others (1994) yields $\mu_{s m o}=0$.

In this paper, the moduli formed by grains and gas hydrate are computed from equations 6 and 7 using the following apparent water-filled porosity $\left(\phi_{a s}\right)$. For the matrix formed by the grains (that is, $K_{s m}$ and $\mu_{s m}$ ), $\phi_{a s}=\phi_{w}+\varepsilon \phi_{h}$ is used for the porosity in equations 6 and 7. Therefore,

$$
K_{s m}=\frac{K_{s}\left(1-\phi_{a s}\right)}{\left(1+\alpha \phi_{a s}\right)} \quad \text { and } \quad \mu_{s m}=\frac{\mu_{s}\left(1-\phi_{a s}\right)}{\left(1+\gamma \alpha \phi_{a s}\right)}
$$

The term $\varepsilon \phi_{h}$ in the apparent porosity is a small number when $\varepsilon$ is small and accounts for the smaller impact of gas hydrate accumulation relative to compaction on velocity. The logic behind using the apparent porosity instead of the water-filled porosity $\left(\phi_{w}\right)$ is that the velocity increase owing to accumulating gas hydrate is less than that expected from porosity reduction due to compaction. When $\varepsilon=0$, the apparent porosity is the same as the water-filled porosity and the calculated velocities using LCAM-13 with $\varepsilon=0$ are higher than those measured, as shown later in this report.

For the matrix formed by the gas hydrate phase (that is, $K_{h m}$ and $\left.\mu_{h m}\right), \phi_{a h}=1-\phi_{h}$ is used as the apparent porosity. In other words,

$$
K_{h m}=\frac{K_{h}\left(1-\phi_{a h}\right)}{\left(1+\alpha \phi_{a h}\right)} \quad \text { and } \quad \mu_{h m}=\frac{\mu_{h}\left(1-\phi_{a h}\right)}{\left(1+\gamma \alpha \phi_{a h}\right)}
$$


Note that the major differences among Leclaire and others (1994), Carcione and Tinivella (2000), and this report are in the calculation of the moduli of these matrices. For example, Leclaire and others (1994) used constant $K_{s m}$ and $\mu_{s m}$, Carcione and Tinivella (2000) used a constant $K_{s m}$ but a variable $\mu_{s m}$, depending on the gas hydrate concentration as shown in equation 10, and this report uses variable $K_{s m}$ and $\mu_{s m}$, depending on the amount of gas hydrate concentration.

The dominant contribution of gas hydrate to velocities comes from equation 11 , which indicates that the frame moduli increase as the water-filled porosity decreases, similar to the effect of compaction on velocity. The cementation effect on shear modulus is ignored, meaning the aforementioned approach treats the gas hydrate as a load-bearing component of sediments.

\section{Dissipation potential}

The dissipation potential (D) used by Leclaire and others (1994) has the following form:

$$
2 \mathbf{D}=b_{11}\left[\left(\frac{\partial u_{1}}{\partial t}-\frac{\partial u_{2}}{\partial t}\right)\right]^{2}+b_{33}\left[\left(\frac{\partial u_{2}}{\partial t}-\frac{\partial u_{3}}{\partial t}\right)\right]^{2}
$$

where $u_{1}, u_{2}$, and $u_{3}$ are displacements in the solid grain, water, and gas hydrate, respectively, and $b_{11}$ and $b_{33}$ are the friction coefficients between solid and water and between gas hydrate and water. As indicated in equation 13, dissipation caused by relative velocity between grains and gas hydrate is ignored under the assumption that there is no direct contact between grains and gas hydrate. In this paper, the friction between solid and gas hydrate is formally included by adding

$$
b_{13}\left[\left(\frac{\partial u_{1}}{\partial t}-\frac{\partial u_{3}}{\partial t}\right)\right]^{2}
$$

to equation 13. Because the term $b_{13}$ is included in the friction matrix, the elements of $\mathbf{A}$, shown in equation 1 , are different from Leclaire and others (1994). The theoretical derivation of $b_{13}$ in the friction matrix is beyond the scope of the current study. However, using the approach of Guerin and Goldberg (2005), $b_{13}$ is estimated in such a way that the calculated attenuations using LCAM-13 fit the observed attenuations.

\section{Velocity and Attenuation Modeling}

Figures 1 and 2 show velocities and attenuations calculated for a sediment having $\phi=0.32, C_{v}=0.1$ (fractional volume clay content), and $C_{h}=0.3$ using the LCAM-13 with constants listed in table 1 with $\varepsilon=0.12$. The result of the LCAM-13 without $b_{13}$ is shown in figure 1 , and the result with $b_{13}$, which is given by $10^{9} \phi_{h}{ }^{2} \mathrm{~kg} \mathrm{~m}^{-3} \mathrm{~s}^{-1}$, is shown in figure 2 .

Figure 1 indicates that fast $\mathrm{P}$ - and $\mathrm{S}$-waves are nearly constant for frequencies to $1 \mathrm{MHz}$, meaning they are practi- cally nondispersive (fig. $1 \mathrm{~A}: V_{p 1}$ is about $2.5 \mathrm{~km} / \mathrm{s}$ and $V_{s 1}$ is about $1.0 \mathrm{~km} / \mathrm{s}$ ). The slow $\mathrm{P}$-waves are dispersive, but the slow $\mathrm{S}$-wave is non-dispersive. The calculated attenuation is small for the fast $\mathrm{P}$ - and $\mathrm{S}$-waves, as expected from their nondispersive behavior (fig.1B). Comparing figures $1 \mathrm{~B}$ and $1 \mathrm{C}$ for frequencies higher than $10 \mathrm{kHz}$, the shear wave attenuation $Q_{s 1}{ }^{-1}$ is orders of magnitude higher than the P-wave attenuation $Q_{p}^{-1}$.

In figure 2 , the effects of including friction between grains and gas hydrate can be seen. The fast $\mathrm{P}$ - and $\mathrm{S}$-waves are still almost nondispersive, but all slow $\mathrm{P}$ - and $\mathrm{S}$-waves are highly dispersive (fig. 2A). The biggest difference between figures 1 and 2 is in the attenuation of slow waves. Figure 2 indicates that $Q_{p 2}{ }^{-1}$ and $Q_{s 2}{ }^{-1}$ with $b_{13}$ are orders of magnitude higher than those without $b_{13}$. The results shown in figures 1 and 2 indicate that the effect of $b_{13}$ in the LCAM formulation has only a minor change on the fast $\mathrm{P}$ - and $\mathrm{S}$-waves.

\section{Real Data Example}

The Mallik 2L-38 and Mallik 5L-38 wells drilled in the Mackenzie Delta, Canada, provided data for evaluating the three-phase equation. The following summarizes the observed seismic properties of GHBS at these well locations.

(1) Velocities derived from the vertical seismic profiles (VSP) are similar to those from well logging. Well log P-wave velocities were measured using a monopole with a dominant frequency of $12 \mathrm{kHz}$, and S-wave velocities were measured using a dipole tool with the frequency of $2.5 \mathrm{kHz}$. The average of P-wave velocities derived from the surface VSP data is about 4 percent slower than that derived from the well log (Lee and others, in press).

(2) P-wave attenuation derived from the well logs indicates that attenuation increases almost linearly as gas-hydrate concentration increases and is represented by Guerin and others (2005) as:

$$
Q_{p}^{-1}=0.0342+0.076 C_{h}
$$

The average gas hydrate concentration at the Mallik 2L-38 well or Mallik 5L-38 well is about 30 percent, with concentrations reaching 90 percent (Lee and Collett, 1999; 2005). The P-wave attenuation of GHBS at 30 percent saturation predicted by equation 14 is about $Q_{p}^{-1} \approx 0.057$.

Using cross-hole seismic data, Pratt and others (2005) estimated $Q_{p}^{-1}$, in the absence of gas hydrate, is on the order of 0.01 , but the presence of gas hydrate increases the apparent values of $Q_{p}^{-1}$ to more than 0.1 in places. Assuming that $Q_{p}^{-1}=0.1$ is the attenuation of gas hydrate-bearing sediments with $C_{h}=0.9$, and two-thirds of the apparent attenuation is because of gas hydrate, similar to monopole attenuation shown in equation 14 , the attenuation at $C_{h}=0.3$ is $Q_{p}^{-1} \approx 0.05$ at a dominant frequency of about $500 \mathrm{~Hz}$ for the cross-hole data.

VSP data indicate that non-GHBS is on the order of $Q_{p}^{-1} \approx 0.013$, whereas the average attenuation of GHBS is 

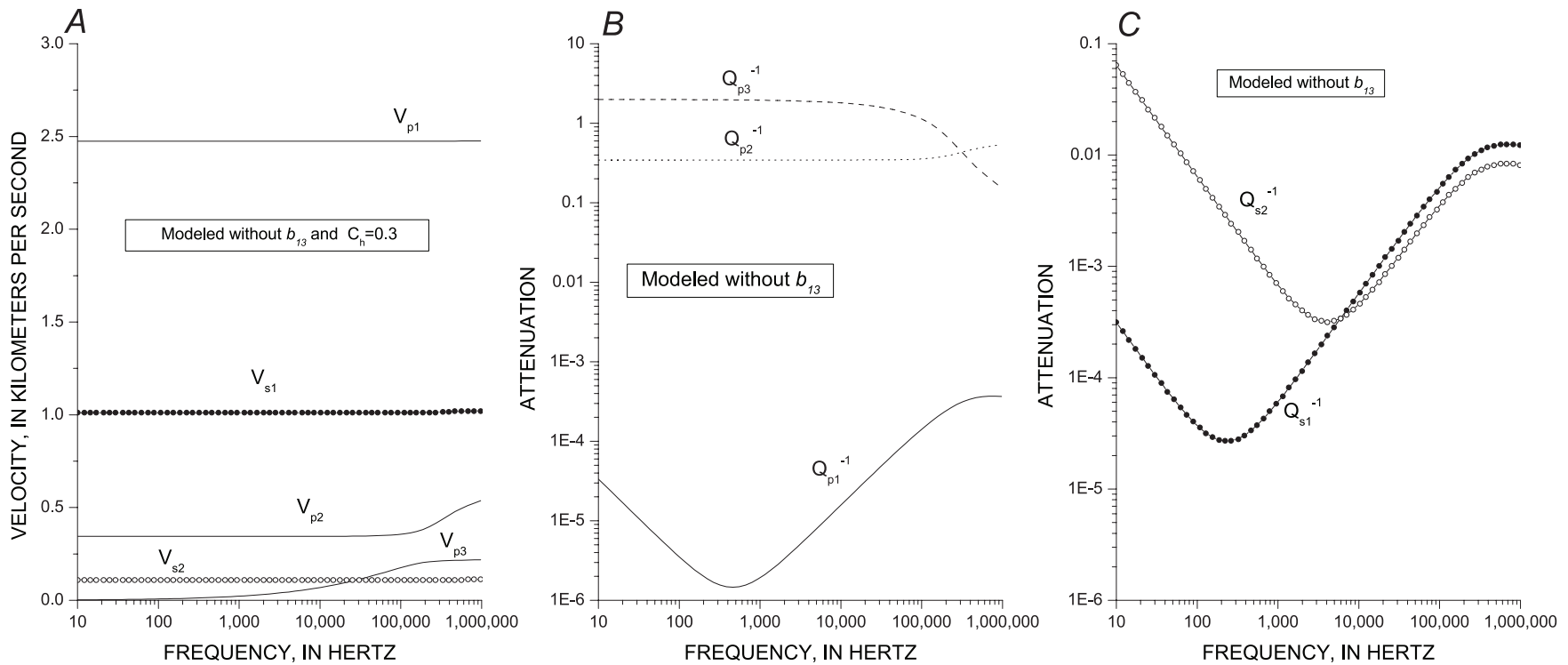

Figure 1. Modeled velocities and attenuations using LCAM-13 without $b_{13}$. (A) Velocities. (B) P-wave attenuation. (C) S-wave attenuation.
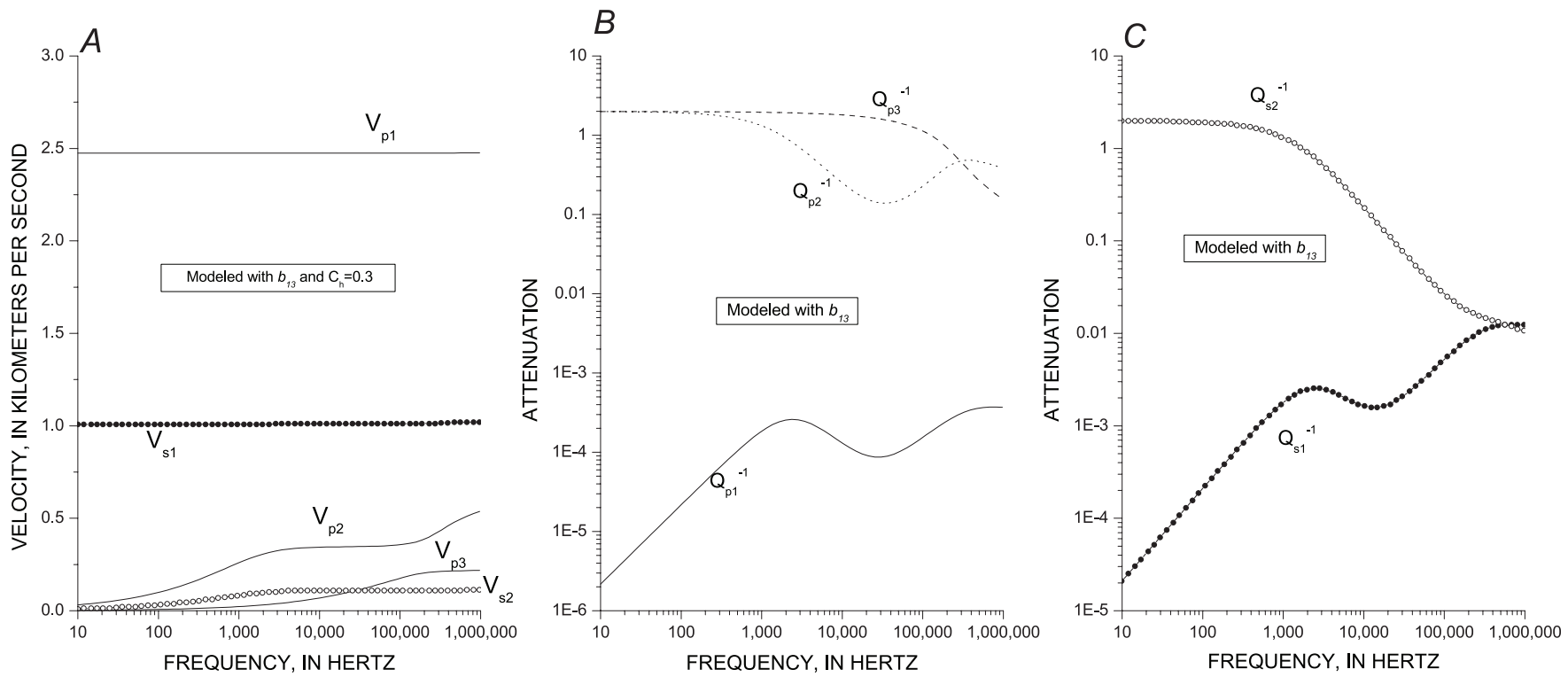

Figure 2. Modeled velocities and attenuations using LCAM-13 with $b_{13}$ which is given by $10^{9} \phi_{n}^{2} \mathrm{~kg} \mathrm{~m}^{-3} \mathrm{~s}^{-1}$. The gas hydrate saturation is 0.3. (A) Velocities. (B) P-wave attenuation. (C) S-wave attenuation.

Table 1. Constants used for the modeling.

[GPa, gigapascal; kg/m³, kilogram per cubic meter; $\mathrm{mD}$, millidarcy; $\mathrm{cP}$, centipoise]

\begin{tabular}{lllll}
\hline$K_{s}=38 \mathrm{GPa}$ & $\mu_{s}=44 \mathrm{GPa}$ & $\rho_{s}=2,650 \mathrm{~kg} / \mathrm{m}^{3}$ & $\kappa_{s o}=100 \mathrm{md}$ & $r_{13}=0.5$ \\
$K_{c}=20.9 \mathrm{GPa}$ & $\mu_{c}=6.85 \mathrm{GPa}$ & $\rho_{c}=2,580 \mathrm{~kg} / \mathrm{m}^{3}$ & $\kappa_{h o}=\kappa_{s o} \times 10^{6} \mathrm{md}$ & $r_{23}=0.5$ \\
$K_{h}=6.41 \mathrm{GPa}$ & $\mu_{h}=2.54 \mathrm{GPa}$ & $\rho_{h}=910 \mathrm{~kg} / \mathrm{m}^{3}$ & $\eta=1.8 \mathrm{cP}$ & $r_{31}=0.5$ \\
$K_{w}=2.29 \mathrm{GPa}$ & $\mu_{w}=0$ & $\rho_{w}=1,000 \mathrm{~kg} / \mathrm{m}^{3}$ & $C_{v}=0.1$ & $r_{12}=0.5$ \\
$\phi=0.32$ & $\alpha=25$ & & \\
\hline \multicolumn{5}{l}{ Subscript $c$ stands for clay. Unless parameters are specifically specified, these parameters were used in the modeling. }
\end{tabular}

Subscript $c$ stands for clay. Unless parameters are specifically specified, these parameters were used in the modeling. 
$Q_{p}^{-1} \approx 0.006$ (Lee and others, in press). Unlike the monopole or cross-hole data, the attenuation of GHBS of VSP data with a dominant frequency of $60 \mathrm{~Hz}$ is less than that of non-GHBS.

(3) S-wave attenuation derived from well logs also indicates that attenuation increases almost linearly as gas hydrate concentration increases and is represented by Guerin and others (2005) as:

$$
Q_{s}^{-1}=0.0615+0.134 C_{h}
$$

Therefore, $Q_{s}^{-1} \approx 0.1$ at $C_{h}=0.3$. There are no other available $S$-wave attenuation data measured at other frequencies.

Figure 3 shows calculated and measured velocities and attenuations for well log data acquired at Mallik 5L-38. The gas hydrate concentrations shown in figure $3 \mathrm{~A}$ are derived from the nuclear magnetic resonance (NMR) porosity, as shown in Kleinberg and others (2005). The parameters for three-phase equation are identical to those for figure 2 .

Calculated velocities agree well with those measured using monopole and dipole waveforms. The calculated attenuations, however, are much smaller than observed.

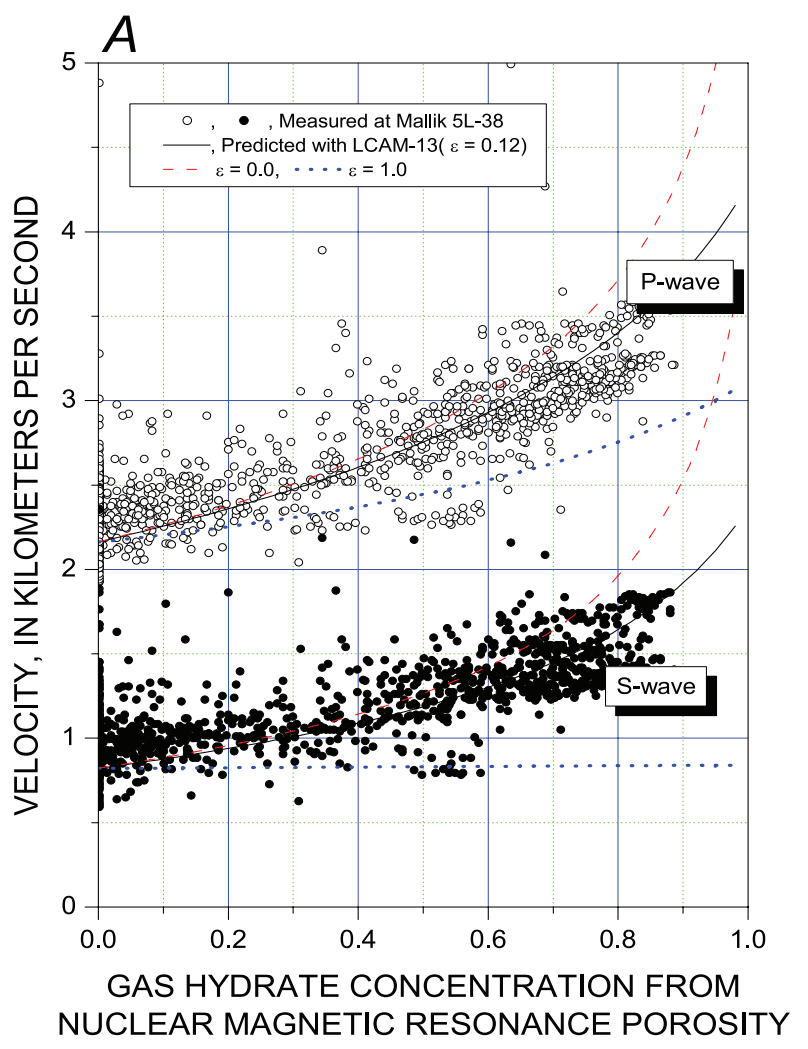

\section{Discussion}

\section{Velocity}

Velocities calculated using the present method, with $\alpha=25$, and $\varepsilon=0.12$, agree well with the observed velocities. The consolidation parameter $\alpha$ can be estimated from the non-GHBS as shown in Lee (2005). Figure 3A also shows the calculated velocities using different values of $\varepsilon$. When $\varepsilon=1$, which is similar to the Leclaire and others (1994) approach, the calculated velocities are much smaller than observed velocities, and shear velocities are almost independent of gas hydrate concentration. The result with $\varepsilon=1$ is the same as the result of the model that assumes gas hydrate floats in the pore fluid and increases seismic velocities primarily by increasing the moduli of the pore fluid (Helgerud, 2001). On the other hand, when $\varepsilon=0$ the calculated velocities are much higher than the measured velocities, but the relation between $V_{p}$ and $V_{s}$ is similar to the measured relation. The result with $\varepsilon=0.12$ agrees closely with measured velocities and calculated velocities using the modified Biot-Gassmann theory by Lee (Lee and Collett, 2005) for gas hydrate saturations less than about 80 percent.

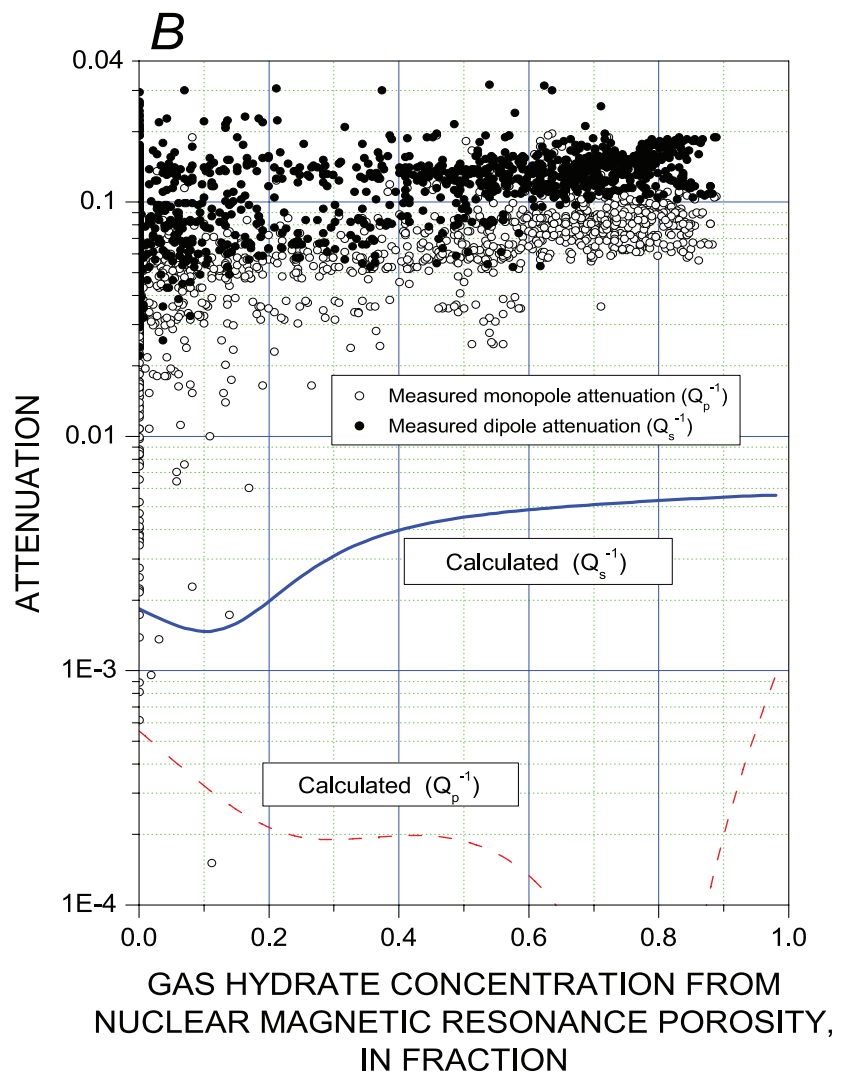

Figure 3 Measured well log velocities and attenuation at the Mallik $5 \mathrm{~L}-38$ well, Mackenzie Delta, Canada, and calculated velocities and attenuations using the LCAM-13 with $b_{13}=10^{9} \phi_{n}^{2} \mathrm{~kg} \mathrm{~m}^{-3} \mathrm{~s}^{-1}$. (A) Velocities. (B) Attenuations. 


\section{Estimation of gas hydrate amounts using velocity}

Figure 4 shows gas hydrate concentrations estimated from the P-wave velocity using the LCAM-13 compared with those estimated from the NMR porosity. The parameters for the LCAM-13 are identical to the previous examples except in porosity and in clay volume content, which are taken directly from the well logs (Collett and others, 2005).

Velocity-based gas hydrate saturation estimates depend on how acoustic effects of the pore-scale interaction between gas hydrate and the host sediment are modeled, and therefore vary depending on the velocity model. Gas hydrate saturations based on the NMR log, however, depend only on the accuracy of the log and on the bulk volume of gas hydrate present, irrespective of pore-scale interactions between gas hydrate and the host sediments. Therefore, gas hydrate estimations from the NMR log can serve as a reference. The excellent agreement between the saturations shown in figure 4 implies that the employed velocity model, which assumes gas hydrate is a load-bearing component of the system, is accurate for the well $\log$ velocities measured at the Mallik 5L-38 well site.

\section{Attenuation}

Comparing figures $1 \mathrm{C}$ and $2 \mathrm{C}$, accounting for frictional motion between grains and gas hydrate by including the $b_{13}$ term increases the predicted attenuation. As figure 5 shows, dependence of attenuation on hydrate content varies with the $b_{13}$, the attenuation changing more noticeably for the S-wave than for the P-wave.

The calculated attenuations without the $b_{13}$ term (fig. 5A) show that $\mathrm{P}$-wave and $\mathrm{S}$-wave attenuations initially decrease as gas hydrate concentration increases, then increase for hydrate saturations greater than 80 percent. Attenuations calculated with $b_{13}=0.25 \times 10^{9} \phi_{h}{ }^{2} \mathrm{~kg} \mathrm{~m}^{-3} \mathrm{~s}^{-1}$, however, show a more complicated dependence on gas hydrate saturation (fig. 5B). Including $b_{13}$, the attenuation decrease with respect to gas hydrate saturation is slower than that calculated without $b_{13}$. The $\mathrm{P}$-wave attenuation at $12 \mathrm{kHz}$ is orders of magnitude smaller than the $\mathrm{S}$-wave attenuation at $2.5 \mathrm{kHz}$ for all ranges of gas hydrate saturation.

S-wave attenuation is sensitive to the magnitude of $b_{13}$; figure 5B shows the result of attenuation with $b_{13}=0.25 \times 10^{9} \phi_{h}{ }^{2} \mathrm{~kg} \mathrm{~m}^{-3} \mathrm{~s}^{-1}$, which is one-fourth of the $b_{13}$ value used in figure $3 \mathrm{~B}$. The $\mathrm{P}$-wave attenuation is still small, whereas the S-wave attenuation increases significantly as gas hydrate saturation increases.

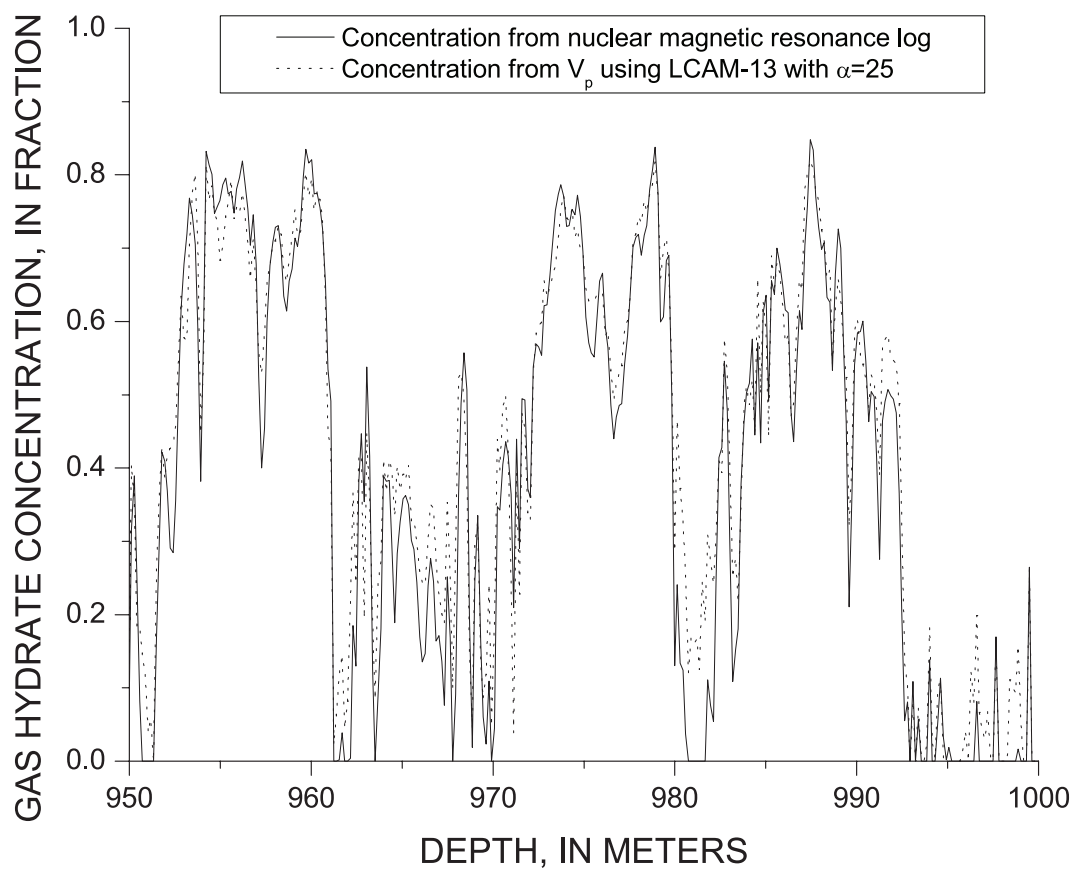

Figure 4. Estimated gas hydrate concentrations from the P-wave using the LCAM-13 and from the nuclear magnetic resonance porosities at the Mallik 5L-38 well, Mackenzie Delta, Canada. 


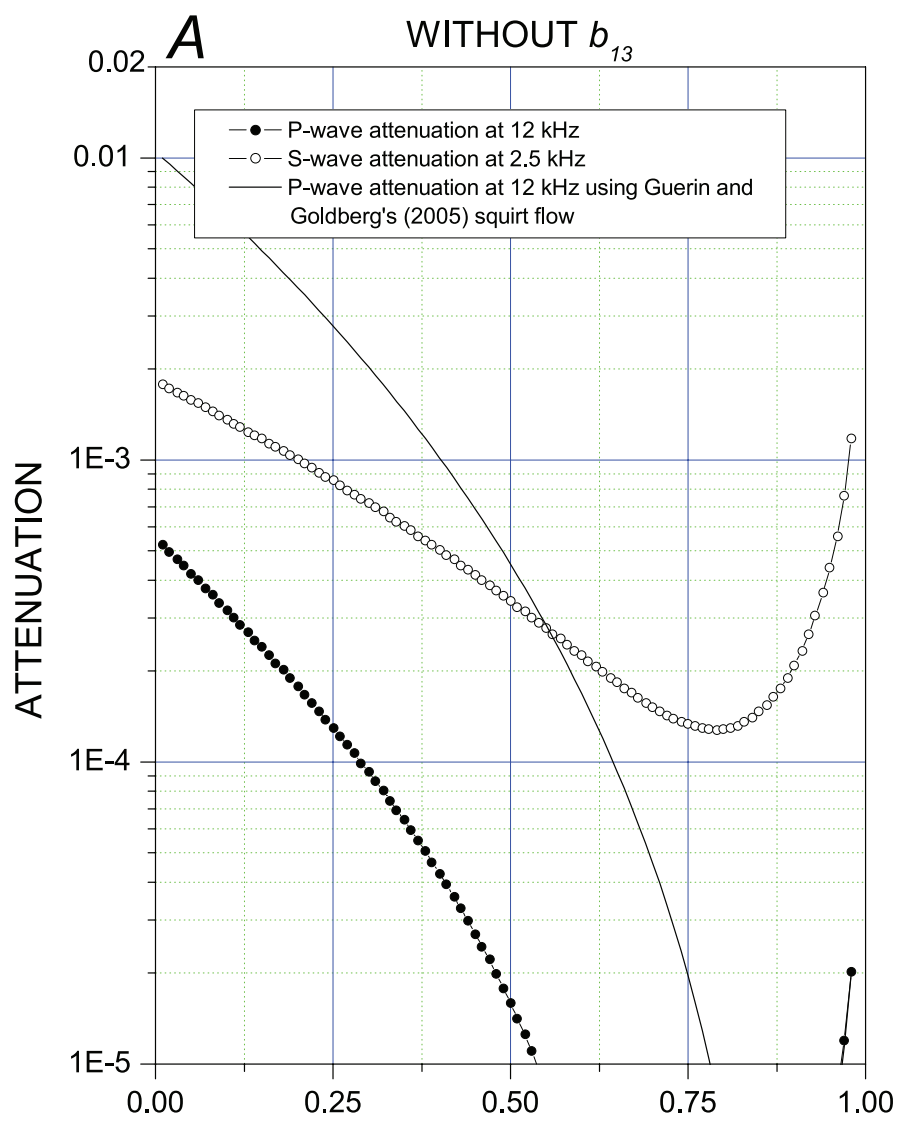

GAS HYDRATE CONCENTRATION,IN FRACTION

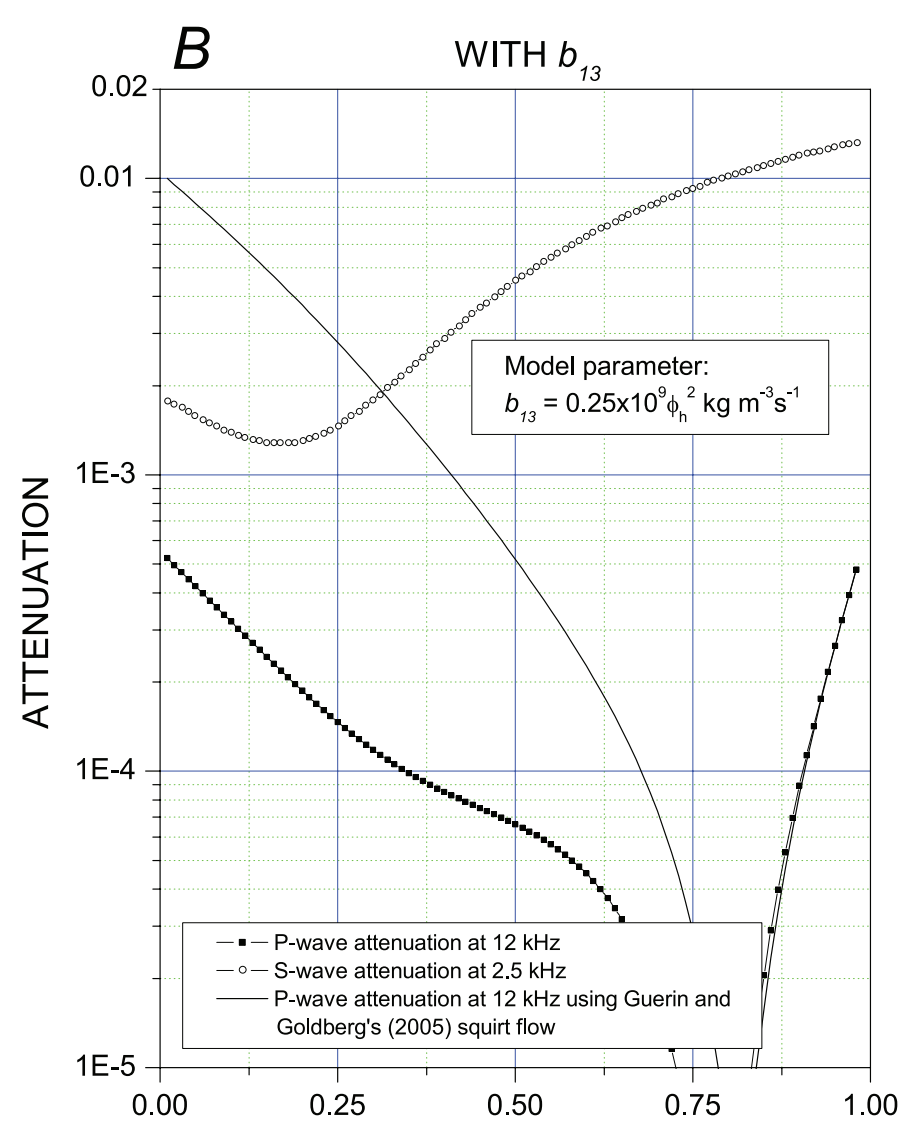

GAS HYYDRATE SATURATION, IN FRACTION

Figure 5. (A) Calculated attenuation without $b_{13}$ term at 12 kilohertz (kHz) and $2.5 \mathrm{kHz}$. (B) Calculated attenuation at $12 \mathrm{kHz}$ and $2.5 \mathrm{kHz}$ with $b_{13}=0.25 \times 10^{9} \phi_{h}^{2} \mathrm{~kg} \mathrm{~m}^{-3} \mathrm{~s}^{-1}$.

Numerical results indicate that the $\mathrm{S}$-wave attenuation is maximized for $b_{13}=0.25 \times 10^{9} \phi_{h}^{2} \mathrm{~kg} \mathrm{~m}^{-3} \mathrm{~s}^{-1}$ and that $b_{13}$ affects the $\mathrm{S}$-wave attenuation more than the $\mathrm{P}$-wave attenuation.

As shown in figure 3B, calculated attenuations are far lower than observed estimates at the Mallik 5L-38 well. Because causality requires a specific relationship between velocity and attenuation, a large attenuation is generally associated with high velocity dispersion (Dvorkin and Uden, 2004). If high attenuation occurs at $12 \mathrm{kHz}$ for the $\mathrm{P}$-wave and $2.5 \mathrm{kHz}$ for the $\mathrm{S}$-wave, the $\mathrm{P}$-wave and $\mathrm{S}$-wave velocities from $60 \mathrm{~Hz}$ VSP data would have been much less than the well $\log$ velocities. However, Sakai (1999) and Lee and others (in press) show that $V_{p}$ and $V_{s}$ estimated from VSP data are comparable to measured well log velocities at the Mallik 2L-38 well, indicating negligible velocity dispersion, consistent with small calculated attenuations.

\section{Comparison with other theories}

Several proposed attenuation mechanisms can account for the counterintuitive attenuation increase with increasing velocity (or gas hydrate concentration) observed at the Mallik sites.
One example is attenuation caused by a squirt flow (Dvorkin and Nur, 1993; Dvorkin and others, 1994, 1995). Squirt flow attenuation is orders of magnitude higher than predicted based on Biot flow. Figure 6 shows an example of velocities and attenuations calculated using the squirt flow theory by Dvorkin and others (1995) using a squirt length of $0.4 \mathrm{~mm}$ and model parameters identical to the result shown in figures 1 and 2 , such as porosity, clay content, permeability, viscosity and gas hydrate concentration. The result indicates high $\mathrm{P}$-wave velocity dispersion, increasing from about $2.5 \mathrm{~km} / \mathrm{s}$ for frequencies less than about $100 \mathrm{kHz}$ to $3.5 \mathrm{~km} / \mathrm{s}$ for frequencies greater than 1 megahertz (MHz). Because significant dispersion occurs above $100 \mathrm{kHz}$, the predicted velocities are close to measured velocities shown in figure 3 .

To match observations at the Mallik wells, squirt length and permeability can be adjusted. Decreasing the squirt flow length decreases the attenuation while increasing the frequencies of peak attenuation and the onset of velocity dispersion. As permeability decreases, attenuation increases. By adjusting permeability and squirt length, it is possible to predict P-wave attenuation to the order of magnitude observed at the Mallik sites. However, the predicted S-wave attenuation is much less than the predicted P-wave attenuation (fig. 6), in 


\section{Squirt Flow}
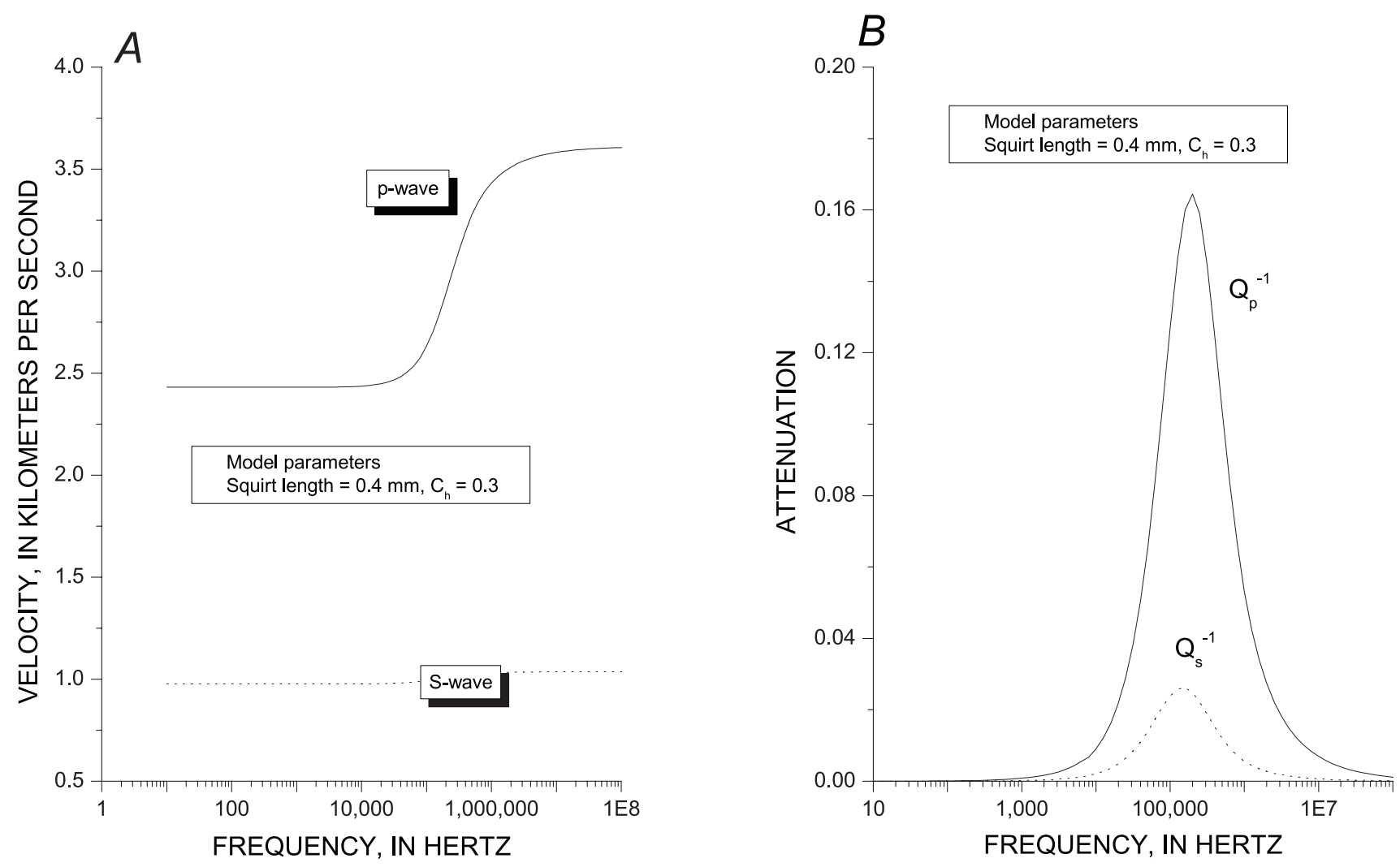

Figure 6. Velocities and attenuations calculated from the squirt flow. (A) Velocities. (B) Attenuations.

contradiction with observations at the Mallik in which S-wave attenuation exceeds the P-wave attenuation (fig. 3). Also, the squirt flow mechanism does not predict high attenuation at low frequencies. Therefore, the squirt flow mechanism alone does not explain the attenuation observed at the Mallik 5L-38 well site.

Klimentos and MaCann (1990) presented a relation between $\mathrm{P}$-wave attenuation and clay content and porosity at $1 \mathrm{MHz}$ and 40 megapascals (MPa). The dominant part of $\mathrm{P}$-wave attenuation is attributed to the clay content of the sediments, and attenuation is linearly related to the clay volume content. They analyzed the observed attenuation using particle suspension models of Sewell (1910) and Urick (1948) and concluded that there is reasonable order of magnitude agreement between the theoretical and experimental results. Similarities in the linear dependence of attenuation on clay content and gas hydrate concentration indicate that the particle suspension theory could be applied to GHBS.

In the particle suspension theory, attenuation arises from the viscous interaction between pore fluid and suspended particles. Sewell's (1910) model assumed that particles are of such great density that they do not participate in the acoustic motion of the fluid and gives the upper boundary of the suspension model. At the other extreme, Urick's (1948) model assumed that particles having similar density to the fluid participate in the acoustic vibration, providing a lower bound of the suspension model. These bounds differ by orders of magnitude, however, and provide only a loose constraint on the measured attenuation. Moreover, Urick's (1948) theory predicts decreases in attenuation for volume concentration of the particles exceeding 20 percent, contradicting the behavior of the observed attenuation in GHBS. The particle suspension models of Sewell (1910) or Urik (1948) do not appear to be viable for the Mallik site.

Guerin and Goldberg (2005) obtained a significant attenuation increase by including cementation in $\mu_{13}$, making the inertial coupling coefficient, and including squirt flow into $\mathrm{R}_{12}$, $\mathrm{R}_{22}$, and $\mathrm{R}_{23}$ (see eq. 1). As mentioned by Guerin and Goldberg (2005), the inclusion of squirt flow only affects the P-wave attenuation. Figure 5 indicates that the inclusion of squirt flow proposed by Guerin and Goldberg (2005) in LCAM-13 increases the P-wave attenuation by an order of magnitude. However, even adding the attenuative elements mentioned by Guerin and Goldberg (2005) does not cause the attenuation to increase enough to agree with the measured attenuation at the Mallik 5L-38; the calculated attenuations are still much less than the measured attenuations. 
Failure to predict high attenuation for GHBS may result from: (1) theoretical inadequacies in the models previously discussed, and (2) interpretive inadequacies concerning the data itself. Recently, Lee and Waite (2007) questioned the magnitude of attenuation analyzed at the Mallik site by Guerin and others (2005). They argued that an amplitude loss owing to the source coupling to the surrounding medium, rather than intrinsic attenuation of the GHBS itself, accounts for at least half the observed amplitude loss at the Mallik site. It is unclear whether the failure of current theory to predict attenuations high enough to compare with observed attenuation levels is caused by incompleteness of the theory, by observational inadequacies, or both. Estimating gas hydrate from acoustic data using velocity and attenuation is, however, important. Accordingly, attenuation models proposed in the future need to honor the causality condition relating sonic velocity and attenuation so as to demonstrate not only a match to observed attenuation, but to observed velocities as well.

\section{Conclusions}

A modified three-phase percolation theory that includes frictional interactions between the sediment matrix and gas hydrate accurately predicts the velocities measured at the Mallik 5L-38 well. This approach yields accurate P- and S-wave velocities that can be used to accurately estimate the gas hydrate content of the sediments.

As with attenuation models based on squirt flow and frictional motion between sediment grains and gas hydrate, however, the model presented here fails to predict attenuations comparable to measured attenuations at the Mallik 5L-38 well. All attenuation models considered in this study predict attenuations that are orders of magnitude less than measured attenuations in the frequency range between 60 and 12,000 Hz at the Mallik site. Failure of the current state-of-the-art attenuation models when considering the Mallik site indicates that the proposed attenuation mechanisms and attenuation data interpretation need to be reconsidered. To be viable, future attenuation models need to reflect the causal relation between velocity and attenuation by accurately predicting both.

\section{References Cited}

Biot, M.A., 1956, Theory of propagation of elastic waves in a fluid-saturated porous solid. a. Low-frequency range, b. Higher frequency range: Journal of Acoustical Society of America, v. 28, p. 168-191.

Carcione, J.M., and Tinivella, U., 2000: Bottom-simulating reflectors: Seismic velocities and AVO effects: Geophysics, v. 65 , p. 54-67.
Collett, T.S., Lewis, R.E., and Dallimore, S.R., 2005, JAPEX/ JNOC/GSC et al. Mallik 5L-38 gas hydrate production research well downhole well-log and core montages, in Dallimore, S.R., and Collett, T.S., eds., Scientific results from the Mallik 2002 gas hydrate production research well program, Mackenzie Delta, Northwest Territories, Canada: Geological Survey of Canada, Bulletin 586, 23 p.

Dallimore, S.R., and Collett, T.S, 1999, Regional gas hydrate occurrences, permafrost conditions, and Cenozoic geology, Mackenzie Delta area, in Dallimore, S.R., Uchida, T., and Collett, T.S., eds., Scientific results from JAPEX/JNOC/ GSC Mallik 2L-38 gas hydrate research well, Mackenzie Delta, Northwest Territories, Canada: Geological Survey of Canada Bulletin 544, p. 31-43.

Diallo, M.S., and Appel, E., 2000, Acoustic wave propagation in saturated porous media: Reformulation of the Biot/ Squirt flow theory: Journal of Applied Geophysics, v. 44, p. 313-325.

Dvorkin, J., Mavko, G., and Nur, A., 1995, Squirt flow in fully saturated rocks: Geophysics, v. 60, p. 97-107.

Dvorkin, J., Nolen-Hoeksema, R., and Nur, A., 1994, The squirt-flow mechanism: Macroscopic description: Geophysics, v. 59, p. 428-438.

Dvorkin, J., and Nur, A., 1993, Dynamic poroelasticity: A unified model with the squirt and Biot mechanism: Geophysics, v. 58, p. 524-533.

Dvorkin, J., and Uden, R., 2004, Seismic wave attenuation in methane hydrate reservoir: The Leading Edge, v. 23, p. 730-734.

Guerin, G., and Goldberg, D., 2001, Sonic waveform attenuation in gas hydrate-bearing sediments from the JAPEX/ JNOC/GSC Mallik 2L-38 research well, Mackenzie Delta, Canada: Journal of Geophysical Research, v. 107, no. B5, 2088, 10.1029/2001JB000556.

Guerin, G., and Goldberg, D., 2005, Modeling of acoustic wave dissipation in gas hydrate-bearing sediments: Geochemistry, Geophysics, Geosystems, v. 6, Q07010, doi:10.1029/2005GC000918.

Guerin, G., Goldberg, D., and Collett, T., 2005, Sonic attenuation in the JAPEX/JNOC/GSC et al. Mallik 5L-38 gas hydrate production research well, in Dallimore, S.R., and Collett, T.S., eds., Scientific result from the Mallik 2002 gas hydrate production research well program, Mackenzie Delta, Northwest Territories, Canada: Geological Survey of Canada, Bulletin 586, 9 p.

Guerin, G., Goldberg, D., and Melsterl, A., 1999, Characterization of in situ elastic properties of gas hydrate-bearing sediments on the Blake Ridge: Journal of Geophysical Research, v. 104, p. 17,781-17,796. 
Helgerud, M.B., 2001, Wave speeds in gas hydrate and sediments containing gas hydrate: A laboratory and modeling study. Doctoral Thesis, Stanford, Palo Alto, Calif., 249 p.

Kleinberg, R.L., Flaum, C, and Collett, T.S., 2005, Magnetic resonance log of JAPEX/JNOC/GSC et al. Mallik 5L-38 gas hydrate production research well: Gas hydrate saturation, growth habit, relative permeability, in Dallimore, S.R., and Collett, T.S., eds., Scientific results from the Mallik 2000 gas hydrate production research well program, Mackenzie Delta, Northwest Territories, Canada: Geological Survey of Canada, Bulletin 585, $10 \mathrm{p}$.

Klimentos, T., and MaCann, C., 1990, Relationships among compressional wave attenuation, porosity, clay content and permeability in sandstones: Geophysics, v. 55, p. 998-1014.

Kuster, G.T., and Toksöz, M.N., 1974, Velocity and attenuation of seismic waves in two-phase media: Part1, Theoretical formulations: Geophysics, v. 59, p. 587-606.

Leclaire, P., Cohen-Tenoudji, F., and Aguirre-Puente, J., 1994, Extension of Biot's theory of wave propagation to frozen porous media: Journal of Acoustical Society of America, v. 96 , p. 3753-3768.

Lee, M.W., 2005, Proposed moduli of dry rock and their application to predicting elastic velocities of sandstones: U.S. Geological Survey Scientific Investigations Report 2005-5119, $14 \mathrm{p}$

Lee, M.W., and Collett, T.S., 1999, Gas hydrate amount estimated from compressional and shear-wave velocities at the JAPEX/JNOC/GSC Mallik 2L-38 gas hydrate research well, in Dallimore and others, eds., Scientific results from JAPEX/JNOC/GSC Mallik 2L-38 gas hydrate research well, Mackenzie Delta, Northwest Territories, Canada: Geological Survey of Canada, Bulletin 544, p. 313-322.

Lee, M.W., and Collett, T.S., 2005, Assessments of gas hydrate concentrations estimated from sonic logs in the Mallik 5L-38 well, N. W. T., Canada, in Dallimore, S.R., and Collett, T.S., eds., Scientific results for Mallik 2002 gas hydrate production research well program, Mackenzie Delta, Northwest Territories, Canada: Geological Survey of Canada, Bulletin 585, 10 p.
Lee, M.W., Collett, T.S., and Agena, W.F., in press, Integration of vertical seismic, surface seismic, and well log data at the Mallik 2L-38 gas hydrate research well, Mackenzie Delta, Canada, in Collett, T.S., Johnson, A., Knapp, C., and Boswell, R., eds., American Association of Petroleum Geologists special volume on gas hydrate.

Lee, M.W., and Waite, W.F., 2007, Amplitude loss of sonic waveform due to source coupling to the medium: Geophysical Research Letters, v. 34, L05303, doi:10.1029/20006GL029015.

Pellenbarg, R.E., and Max, M.D., 2000, Introduction, physical properties, and natural occurrences of hydrate, in Max, M.D., ed., Natural gas hydrate in oceanic and permafrost environments: Kluwer Academic Publishers, p. 1-8.

Pratt, R.G., Hou, F., Bauer, K., and Weber, M., 2005, Waveform tomography images of velocity and inelastic attenuation from the Mallik 2002 crosshole seismic survey, in Dallimore, S.R., and Collett, T.S., eds., Scientific result for Mallik 2002 gas hydrate production research well program, Mackenzie Delta, Northwest Territories, Canada: Geological Survey of Canada, Bulletin 585, 14 p.

Pride, S.R., Berryman, J.G., and Harris, J.M., 2004, Seismic attenuation to wave-induced flow: Journal of Geophysical Research, v. 109, B01201, doi:10.1029/2003JB002639.

Sakai, A., 1999, Velocity analysis of vertical seismic profile (VSP) survey at JAPEX/JNOC/GSC Mallik 2L-38 gas hydrate research well and related problems for estimating gas hydrate concentration, in Dallimore, S.R., Uchida, T., and Collett, T.S., eds., Scientific results from JAPEX/JNOC/ GSC Mallik 2L-38 gas hydrate research well, Mackenzie Delta, Northwest Territories, Canada: Geological Survey of Canada Bulletin 544, p. 323-340.

Sewell, C.T.J., 1910, The extinction of sound in a viscous atmosphere by small obstacles of cylindrical and spherical form: Philosophical Transactions of the Royal Society, v. 210, p. 239-270.

Shatilo, A.P., Sondergeld, C., and Rai, C.S., 1998, Ultrasonic attenuation in Green Pool rocks, northeastern Oklahoma: Geophysics, v. 63, p. 465-478.

Urick, R.J., 1948, The absorption of sound in suspensions of irregular particles: Journal of Acoustical Society of America, v. 20, p. 283-356. 
